\title{
The Comparison of Emotional Intelligence in College Students Participating in Different Levels of Exercise 不同運動參與程度大學生之情緒智力之探討
}

\author{
Gladys Shuk-Fong LI Hsiu-Hua WANG Chang Ning LIAO \\ Graduate Institute of Sport and Leisure Education, \\ National Chung Cheng University, TAIWAN
}

\section{李淑芳 王秀華廖种䁇 \\ 台灣國立中正大學運動休閒教育研究所}

\begin{abstract}
Emotions are an integral and significant aspect of human nature and the motivation for behavior. Regular Exercise participation substantially help individual to maintain and increase positive mood. Purposes: to compare the differences of EQ in the following variables: different level of exercise participation, PE class and non-PE class. Methods: BarOn EQ-I measured the EQ of 326 college students, the data was analyzed by Independent group $t$ ratio, Independent Group ANOVA, and Independent Group MANOVA, using the Statistical Package for the Social Sciences (SPSS), version 10.0. Results: The major findings were as follows: 1) College students participated in higher levels of exercise was significantly $(\mathrm{p}<.05)$ higher than lower levels exercisers in total EQ score, the five composite scores, and the $15 \mathrm{EQ}$ subscale scores; and 2) Students attending physical education class was significantly $(\mathrm{p}<.05)$ higher than the non physical education students in the scores of 'intrapersonal skill', 'interpersonal skill', 'adaptability', 'stress management', and 'general mood'. Conclusion: From the above findings, the more the exercise and the physical education participation, the higher the EQ in the college students was ascertained. The importance of increasing exercise participation and physical education should be reinforced and implemented in the college level. Furthermore, the mind-body linkage has been proved through this research.
\end{abstract}

Key words: Exercise Participation, Emotional Intelligence, Physical Education Class

\section{摘 要}

情緒智力 (Emotional Intelligence, EI) 是察覺, 整合, 瞭解, 及管理情緒之智力; 也是関於瞭解自己及別人, 與別人 建立關係, 適應及因應週遭環境, 更能成功的應付環境需求的自覺能力。透過從事規律運動所帶來的正面回饋, 個人之正向 情緒感受會大為提昇。目的：旨在探討不同運動參與程度與體育課參與情況，對大學生情緒智力表現是否有差異。方法：使用 BarOn EQ-i測量326名大學生之情緒智力, 統計方法分別採用獨立樣本 t考驗、單因子變異數與多因子變異數等加以分析。 結果：一、運動參與程度較高之大學生在情緒智商（Emotional Quotient，EQ）總分、五個EQ分量表、及15項EQ因子之分數, 皆顯著 $(\mathrm{p}<.05)$ 高於運動參與程度較低之大學生。二、參與體育課程之大學生在 $\mathrm{EQ}$ 總分、五個 $\mathrm{EQ}$ 分量表之得分，皆顯著 $(\mathrm{p}<.05)$ 高於無參與體育課程之大學生。結論：大學生運動參與時間愈多, 比運動參與時間較少之大學生有更高的EQ; 再者, 參與體育課程比沒有參與體育課程之大學生有較高的 $\mathrm{EQ}$, 因此, 本研究中顯示出運動參與及體育課對大學生之重要性, 更進而強 化身心一元之理論。

關鍵詞：體育課、EQ 


\section{壹、緒 論}

\section{一、研究背景}

情緒是人的本性, 對於個人的思考、行為動機之模 式深具影響, 關係著個人的人生目標與際遇 (Lazarus \& Lazarus，1994)，它更會促使人們反應出各種不同的行為能 力, 在面臨各種情境時使人們能立即擬定因應計畫 (Goleman， 1995)。心理學者提出正向情緒的重要性, 認為正向情 緒可顯示個人的自信與預測未來的成功 (Bandura, 1996)， 且Goleman (1995)指出, 在了解、辩識情緒的發生與本質, 適時、適所、適地管理及運用自我及他人情緒的能力, 進而 做好情緒管理，提昇情緒商數 (emotional quotient, EQ) , 將可在人生各個領域較佔優勢。情緒商數 (emotional quotient, EQ 即為個人在情緒智力測驗上表現的一個數值指 標, 「EQ」此一名詞近來為社會大眾相當耳熟的名詞, 但 其與情緒智力 (Emotional Intelligence, EI) 間的關係常遭 到混淆。實際上 $\mathrm{EQ}$ 乃是 $\mathrm{EI}$ 經由科學的測量方法後, 所得到的一個數值指標, 用量化的方式評量個人在 EI 能 力的表現, 得以用來做高低、優劣之比較, 因此 EI 與 $\mathrm{EQ}$ 之意涵為相同, 在本研究可以交替應用。

情緒智力 (Emotional Intelligence，EI) 包括了「情 緒」與「智力」兩部分, 代表著個人對自己及他人情緒的察 覺, 以及對情緒做妥善的調整與管理的能力, 情緒智力有助 於消除個人之負向情緒, 並增進人際關係的拓展。Mayor \& Salovey (1997) 將 EI 的內容分為四個層面：1.評估與表 達情緒、2.激發與產生情感以促進思考、3.具備情緒知識與 了解情緒、及4.調整情緒、智力成長等各種能力。而 BarOn (2002) 認認為 EI 強調的是情緒, 個人, 社會, 及生 存的智力層面, 而 EI 比傳統的認知智力對於日常功能更 為重要; Bar-On (2002)將情緒智力定義為察覺, 整合, 膫 解, 及管理情緒之智力; 並指出 EI 是瞭解自己及別人, 與別人建立關係, 適應及因應週遭環境, 使個人更能成功的 應付環境需求的自覺能力。

Goleman (1995) 於其著作中指出個人的成就僅 $20 \%$ 取決於IQ以外, 其餘 $80 \%$ 則為 EQ所影響, 此一説法, 更突 顯出 $\mathrm{EQ}$ 對個人未來成功之重要性。EQ除了能夠預測個人 成功的未來, EQ高者亦有較好的生活適碳能力 (Pelliteri, 1999)、較出色的學業成績表現 (王財印, 2000) 、以及 較佳的社會關係 (Perry，2001), 甚至在心理疾病日益嚴重 的當下, $E Q$ 的提昇更是有助於降低個人的自殺傾向（李孟 儒, 2001）。
也有許多研究指出, 從事運動對大學生情緒的影響, 有助於正向情緒的提昇, 並降低負向情緒 (Szabo，2003)， 當運動帶來正面回饋時, 個人之正向情緒感受會大為提昇 (Turnbull \& Wolfson，2002)。而運動有助於正向情緒之提 昇, 乃是因為運動後人體會產生腦啡（endorphins），其是 一種在腦部與脛下垂體所合成類似嗎啡的化學物質, 而運動 後情緒得以紓解, 主要是由於腦啡能讓人覺得心情放鬆、 愉快、且忘記病苦（張宏亮，1995）。Estivil (1995) 亦指 出, 運動除了能達到令人愉悦及安靜的狀態, 更能使個體暫

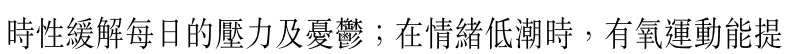
供良好的感覺, 亦可以達到提昇情緒的作用。在運動與整體 情緒之相關研究中顯示, 從事運動不但能有效降低個人的 負向情緒（Szabo，2003）、進一步增進正向情緒 (Biddle, 2000), 更能促使個人保持樂觀態度 (Kavussanu \& McAuley，1995)。至於運動及體育課之參與是否與情緒智力有關 連性, 則有待查證, 亦是本研究主要探討的重點之一。

情緒智力之測量在近年來備受研究情緒智力之學者的 關注, 究竟是自我評量式(self-report test) 之特質情緒智力 (trait EI) 測量, 還是講求實作表現能力 (performance-based) 之能力情緒智力(ability $\mathrm{EI}$ ) 測驗對情緒智力之測量較有代 表性及適切性? Petrides and Furnham (2001) 指出, 特 質情緒智力 (trait EI), 是指對於自己瞭解, 處理, 及應用 情緒資訊能力之行為上的個性及自我知覺; 其測量方式是在 與個性範疇有關的問卷作自我評量。而能力情緒智力 (ability EI, 或 認知情緒智力) 則是指個體瞭解, 處理, 及應 用情緒資訊能力之真正能力; 其測驗工具是要回答「對」或

「錯」之最大能力測驗 (Petrides, Frederickson，\& Furnham, 2004)。

在比較自我陳述情緒智力測量工具及能力情緒智力測量 工具在預測學業成就表現之研究中, O' Connor and Little (2003) 發現 Mayer, Salovey, Caruso Emotional Intelligence Test (MSCEIT, an ability-based measure) 與認知 之指標有高度相關性; 與人格特質之面向卻只有非常低的相 關性; 再者, Bar-On Emotional Quotient Inventory (EQ-I, a self-report measure) 與認知能力没有相關, 卻與人格特 質有顯著的相關。Petrides，Frederickson， and Furnham (2004) 指出特質EI之測量是較明確, 而且Bar-On EQ-i是廣泛而常 被使用的量表; 而要設計出與ability EI相關而能夠客觀作出 對或錯評分之題目對於ability EI測量仍然是深具困難與挑 戰性。本研究旨在探討情緒智力與運動行為之自我知覺, 因 而採用特質情緒智力 (trait EI) 之自我測量的巴安情緒智 商量表 (Bar-On Emotional Quotient Inventory, BarOn EQ-I, 2002)。 


\section{二、研究目的}

本研究之主要目的, 以下分列述之：

（一）比較不同運動參與程度之大學生在 $\mathrm{EQ}$ 總分, 五 個EQ分量表，及15項 $\mathrm{EQ}$ 因子上的差異；

（二）比較有、無參與體育課之大學生在EQ總分, 五 個EQ分量表，及15項EQ因子上的差異。

\section{三、研究限制}

（一）本研究屬追溯性質 (ex post facto), 對於是否 因為學生EQ高所以才比較傾向會從事體育運動 並沒有作控制；及

(二) 本研究旨在探討大學生運動參與時間與情緒智力 之間的關連性，並無進行運動介入之實驗設計， 因此無法推論各相關因子間之因果關係, 更無法 推測其交互影響作用為何。

\section{武・研究方法}

\section{一、研究對象}

本研究在台灣北、中、南三區, 各選出兩至三所公私 立大專院校之日間部大學生（18至22歲、一年級至四年級） 進行抽核調查; 每間學校各抽 2 個班級作為受試樣本, 受試 者是以國內北、中、南部之公私立大專院校一至四年級之日 間部學生為取樣對象，以北部之「國立台灣師範大學」, 「台北商業技術學院」，「中華大學」; 中部包括「台灣體 育學院」,「靜宜大學」; 以及南部的「國立嘉義大學」, 及「高雄師範大學」等共七所大專院校進行問卷調查; 研究 對象將每週「運動參與時間」區分成無（0小時）、低（1-3 小時）、中（4-6小時）、高（6小時以上）四個運動參與程 度; 而在參與體育課之大學生樣本方面, 則直接跟各大學之 體育教師連繋, 於課堂上實施量表發放、填寫、與回收之步 驟。本研究共發放 350 份測驗量表, 扣除無效問卷後, 有效 樣本為326位, 人數分配情況（參見表一）：

\section{表一 本研究之施測對象人數分配表}

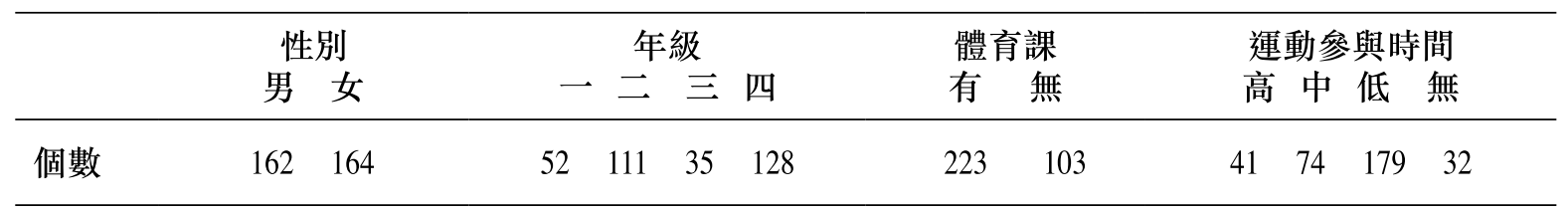

\section{二、研究工具}

\section{（一）個人基本資料}

個人基本資料問卷內容包括受試者之性別、年齡、居住 地區、就讀年級及就讀科系。在運動參與情形方面, 則包括 前一學期至問卷填寫日, 其體育課參與情況、個人每星期從 事運動的平均時數等開放式問題。

(二) EQ量表

1. 本研究採用BarOnEQ-I用來測量受試者之EI, 所測 量之結果則為 $\mathrm{E} Q$, 量表之得分代表情緒智力之程 度。

2. 此量表主要測量與 $\mathrm{EQ}$ 有關之各概念層面, 適合 16 歲以上之受測者使用。此量表共有 133 題, 採 用李考特五等記分法, 需花費30-40分鐘的時間填 寫, 包括五個分量表及十五個因子, 其內部一致 的 $\alpha$ 值介於.69 . 86間。這五個分量表與其所包括 的因子分別為：自我技能（自我情緒認知、自我 表達能力、自我肯定能力、自我提昇能力、獨立 性）、人際技能 （同理心、人際關係、社會責 任）、適應性（解決問題能力、分辦能力、順應 能力）、壓力管理 （壓力容忍度、穩定性）、及 普遍心情（快樂感、樂觀指數）。
3. 此量表提供 $\mathrm{EQ}$ 總體分數; 經由五個分量及 15 個 $\mathrm{EQ}$ 因子之得分, 不但可評量個人對自身情緒之察覺、評 估、運用與自我評價, 亦可評量其人際關係之優劣, 更可測得個人管理壓力.社會適應等之自覺能力。由 此可知BarOn EQ-i情緒量表所涵蓋之EQ層面較廣, 可更深入了解個人對自己EI能力之自我知覺, 較符合 本研究之目的。BarOn EQ-i中文版本於本研究中普 遍取得極高之信度 $(\alpha=.70-.94)$, 除了在 「自我表達能力 $(\alpha=.56)\rfloor$ 、「獨立性 $(\alpha$ $=.061)\rfloor$ 及「分辨力 $(\alpha=.60) 」$ 三個EQ因 子之信度偏低, 主要原因可能在於此三個因子之 部分題目內容, 不容易被台灣大學生所理解, 造 成解讀上的誤差而導致信度偏低之情況。在結構 效度方面, 作者Bar-On提出的概念及BarOn EQ-i 情緒量表定義與其研究成果一致, 相關係數介於 .30 與 .70之間 (Bar-On，2002）證實此EQ-i之分 量表對於EI之測量深具成效, 各分量表間亦具明 確之區別能力。 


\section{三、資料處理與統計分析}

本研究以 SPSS for Windows 10.0 統計套裝軟體進 行各項統計資料分析，並採用 $\mathrm{p}<.05$ 為統計顯著水準， 各項統計方法如下：(一) 獨立樣本 $\mathrm{t}$ 考驗；(二) 單因子變 異數分析 (ANOVA) , 並以Scheffe法做事後比較; (三) 多 因子變異數分析（MANOVA），並以Scheffe法做事後比 較。
參、研究結果

\section{一、大學生運動參與程度在EQ及五個EQ \\ 因子表現上的差異}

以單因子變異數分析去比較四組不同運動參與程度 （高、中、低、無）之大學生在 $\mathrm{EQ}$ 總分上的差異，又以多 因子變異數分析 (MANOVA) 比較四組在5個EQ分量表的 差異，並以Scheffe法做事後比較，結果如下 (參見表二)：

表二 不同運動參與程度在 $\mathrm{EQ}$ 總分及五個 $\mathrm{EQ}$ 分量表上的差異比較

\begin{tabular}{|c|c|c|c|c|c|c|}
\hline & & $\mathrm{N}$ & $\mathbf{M}$ & SD & F值 & 事後比較 \\
\hline \multirow[t]{4}{*}{ EQ總分 } & 高 & 41 & 441.10 & 44.54 & $74.484^{*}$ & 高>中>低>無 \\
\hline & 中 & 74 & 411.70 & 34.55 & & \\
\hline & 低 & 179 & 373.21 & 27.27 & & \\
\hline & 無 & 32 & 352.38 & 36.75 & & \\
\hline \multirow[t]{4}{*}{ 自我技能 } & 高 & 41 & 145.8 & 14.71 & $57.897^{*}$ & 高>中>低>無 \\
\hline & 中 & 74 & 136.69 & 13.33 & & \\
\hline & 低 & 179 & 123.50 & 11.54 & & \\
\hline & 無 & 32 & 115.31 & 12.91 & & \\
\hline \multirow[t]{4}{*}{ 人際技能 } & 高 & 41 & 94.85 & 11.41 & $33.767^{*}$ & 高>中>低=無 \\
\hline & 中 & 74 & 88.64 & 8.93 & & \\
\hline & 低 & 179 & 81.14 & 8.48 & & \\
\hline & 無 & 32 & 79.94 & 9.27 & & \\
\hline \multirow[t]{4}{*}{ 壓力管理 } & 高 & 41 & 68.07 & 9.88 & $48.107^{*}$ & 高>中>低>無 \\
\hline & 中 & 74 & 62.31 & 7.86 & & \\
\hline & 低 & 179 & 55.61 & 7.21 & & \\
\hline & 無 & 32 & 50.03 & 6.85 & & \\
\hline \multirow[t]{4}{*}{ 適應性 } & 高 & 41 & 95.63 & 10.84 & $53.721 *$ & 高>中>低>無 \\
\hline & 中 & 74 & 89.14 & 8.74 & & \\
\hline & 低 & 179 & 81.36 & 6.41 & & \\
\hline & 無 & 32 & 76.87 & 9.74 & & \\
\hline \multirow[t]{4}{*}{ 普遍心情 } & 高 & 41 & 66.71 & 7.98 & $46.669^{*}$ & 高>中>低>無 \\
\hline & 中 & 74 & 62.69 & 6.38 & & \\
\hline & 低 & 179 & 56.50 & 5.74 & & \\
\hline & 無 & 32 & 52.97 & 7.52 & & \\
\hline
\end{tabular}

${ }^{*} \mathrm{p}<.05$ 
從多變量檢定，發現四組不同運動參與程度（高、中、 低、無）之大學生在EQ五個分量表呈現顯著【 $\Lambda=.568 ，$ $F(15,878)=13.29, p=.000$ 差異。從表二得知, 四組 在 $\mathrm{EQ}$ 總分及五個分量表, 以單因子變異數分析, 及Scheffe 法做事後分析比較, 均達顯著 $(\mathrm{p}<.05)$ 差異, 不同運動
參與程度在 $\mathrm{EQ}$ 總分得分為 : 高 $>$ 中 $>$ 低 $>$ 無 ; 而較高運動 參與程度在五個分量表上皆有較高的得分。不同運動參與程 度 (高、中、低、無) 在15項EQ因子之比較分析（如圖一所 示)。

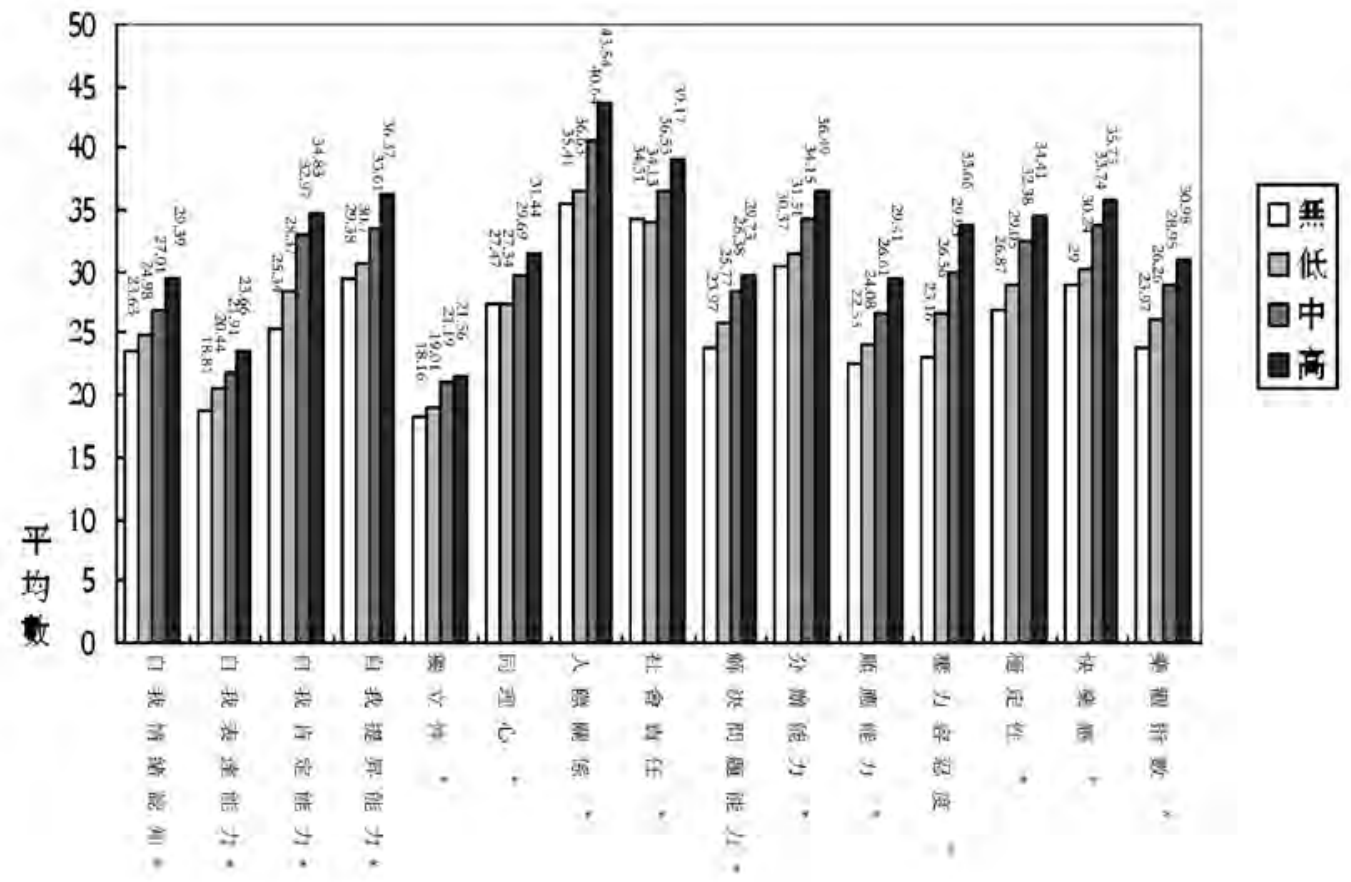

圖一 不同運動參與程度在15項 $\mathrm{EQ}$ 因子之平均數長條圖比較

從多因子變異數分析，四組不同運動參與程度之大學生 在 $\mathrm{EQ}$ 十五個分量表呈現顯著【 $\Lambda=.492, \mathrm{~F}(45,915)=$ $5.494, p=.000$ 差異。由圖一得知, 不同運動參與程度之 大學生在 15 項 $\mathrm{EQ}$ 因子之比較皆達顯著 $(\mathrm{p}<.05)$ 差異, 經 事後比較得知, 較高運動參與程度在 15 項 $\mathrm{EQ}$ 因子上皆有較 高的得分（高 $>$ 中 $>$ 低 $>$ 無）。

\section{二、大學生體育課參與情況在 $\mathrm{EQ}$ 及五倜 $\mathrm{EQ}$ 分量上表 現的差異}

以獨立樣本 $\mathrm{t}$ 檢定考驗大學生之體育課參與情況（有、 無）在 $\mathrm{EQ}$ 總分及五個 $\mathrm{E} Q$ 分量表上是否有差異，又以多因 子變異數分析 (MANOVA) 比較兩組在5個EQ分量表的差 異, 並以Scheffe法做事後比較, 結果如下（參見表三）：

表三 有、無參與體育課在 $\mathrm{EQ}$ 總分及五個 $\mathrm{EQ}$ 分量表上的差異比較

\begin{tabular}{|c|c|c|c|c|c|c|}
\hline & & $\mathrm{N}$ & M & SD & F值 & 差異比較 \\
\hline \multirow[t]{2}{*}{ EQ總分 } & 有 & 223 & 393.52 & 42.80 & $3.172 *$ & 有 > 無 \\
\hline & 無 & 103 & 377.82 & 38.76 & & \\
\hline \multirow[t]{2}{*}{ 自我技能 } & 有 & 223 & 129.83 & 15.69 & $4.859 *$ & 有 > 無 \\
\hline & 無 & 103 & 125.79 & 14.68 & & \\
\hline \multirow[t]{2}{*}{ 人際技能 } & 有 & 223 & 85.44 & 10.17 & $6.372 *$ & 有 > 無 \\
\hline & 無 & 103 & 82.36 & 10.44 & & \\
\hline \multirow[t]{2}{*}{ 壓力管理 } & 有 & 223 & 59.22 & 9.25 & $9.770 *$ & 有 > 無 \\
\hline & 無 & 103 & 55.83 & 8.76 & & \\
\hline \multirow[t]{2}{*}{ 適應性 } & 有 & 223 & 85.54 & 9.79 & $7.782 *$ & 有 > 無 \\
\hline & 無 & 103 & 82.33 & 9.35 & & \\
\hline \multirow[t]{2}{*}{ 普遍心情 } & 有 & 223 & 59.87 & 7.78 & $13.088 *$ & 有 > 無 \\
\hline & 無 & 103 & 56.65 & 6.76 & & \\
\hline
\end{tabular}

$* \mathrm{p}<.05$ 
從多因子變異數分析, 有與無參與體育課之大學生 在EQ五個分量表呈現顯著【 $\Lambda=.941, F(5,320)=$ $4.041, \mathrm{p}=$.001】差異。由表三得知, 有、無參與體育課程 在 $\mathrm{EQ}$ 總分及五個 $\mathrm{EQ}$ 分量表得分上皆達顯著 $(\mathrm{p}<.05)$ 差
異，即有參與體育課程者在 $\mathrm{EQ}$ 總分及五個 $\mathrm{EQ}$ 分量表得分的 表現上皆高於無參與體育課程者。以多因子變異數分析體育 課參與情沉在15個EQ因子得分上的差異, 以Scheffe法做事 後的分析比較, 結果如下 (參見圖二)：

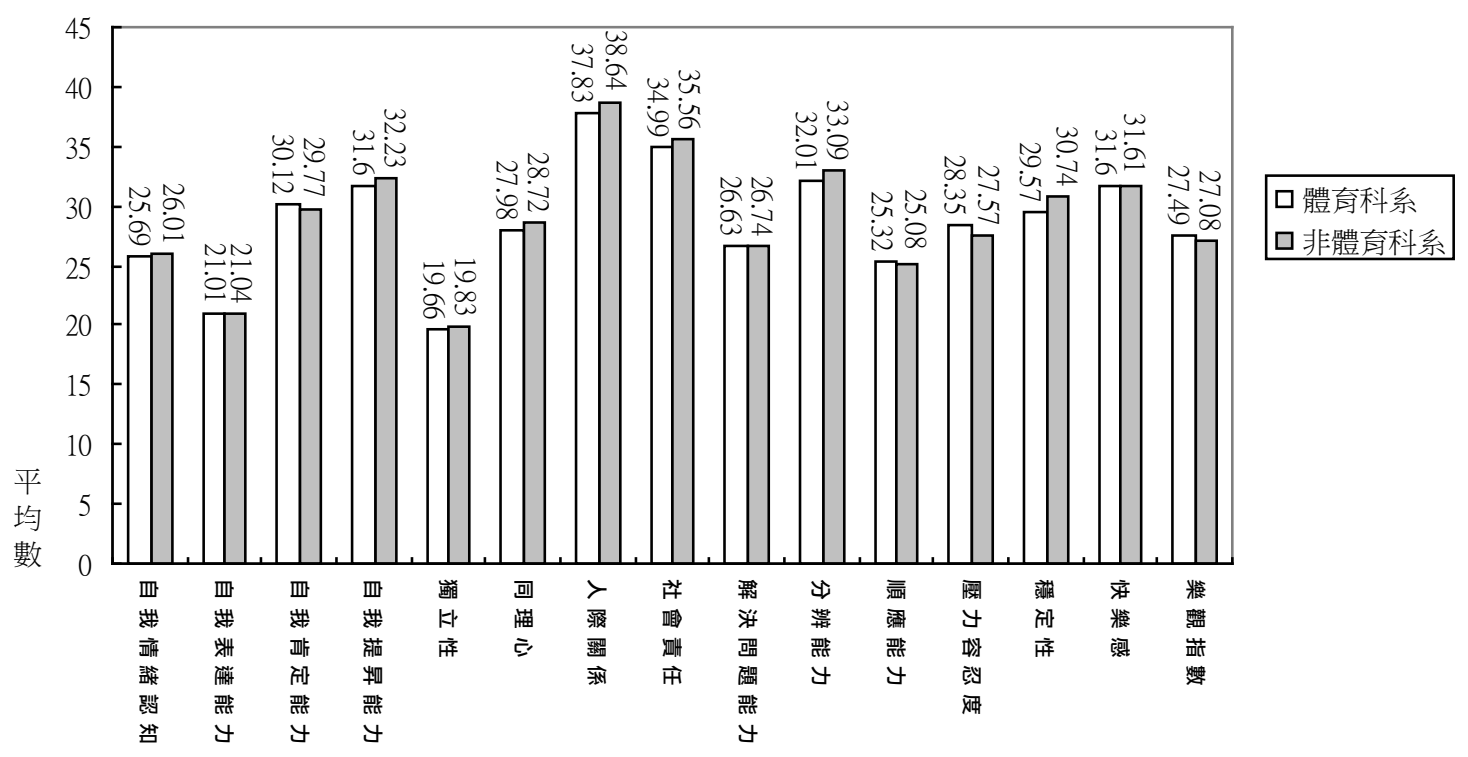

圖二 體育課參與情況在 15 項EQ因子之平均數長條圖比較圖

從多因子變異數分析結果顯示, 有與無參與體育課之 大學生在十五個 $\mathrm{EQ}$ 因子上沒有顯著【 $\Lambda=.933, \mathrm{~F}(15$, 310） $=1.475, p=.113$ 】差異。經過Scheffe法事後比較的 分析, 由圖二得知, 有、無參與體育課程在 15 個 EQ因子得 分比較上, 在「自我表達能力」、「自我提提能力」、「人 際關係」、「順應能力」、「涯力容忍度」、「穩定性」、 「快樂感」、及「樂觀指數」等八個項目達到顯著 $(\mathrm{p}<$ .05) 差異, 有參與體育課組在此八個項目的得分上皆高於無 參與體育課組。

\section{肆、詂論}

\section{一、不同運動參與程度在EQ上的差異比較}

本研究發現運動參與程度較高之大學生在情緒智力 (EI) 上較優於運動參與程度較低者。以上的結果與過去之研 究結果相符合 (Kavussanu \& McAuley, 1995; Kennedy \& Newton, 1997 ; McGowan, Pierce, \& Jordan, 1991; Slaven \& Lee, 1997; Yeung, 1996) •Yeung (1996) 針 對有運動及無運動的澳洲中年婦女為期十二週、每週至少兩 次、每次三十分鐘的有氧運動訓練中發現, 無論是否處於更 年期, 有運動婦女的正向情緒高於靜態活動的婦女。因此, 從事有氧運動會改善情緒狀態 (Yeung, 1996)，降低負向情
緒（壓力、憂银、生氣、疲倦、混亂），增進活力（正向情 緒) (Kennedy \& Newton, 1997; McGowan, Pierce, \& Jordan, 1991); Kavussanu and McAuley (1995) 曾以一 地區性健身俱樂部的會員共188名施以六種樂觀、悲觀、焦 虑和自我效能等有關的問卷, 研究結果發現身體活動性較高 的參與者, 比不做健身運動或低活動量的參與者有更高的樂 觀得分和較低的悲觀得分。而本研究之結果也呈現相同效 益, 高度運動參與者在 $\mathrm{EQ}$ 總分與五個分量表得分方面, 都 顯著高於無參與運動或低度運動參與者。在運動與自我技能 方面, 本研究顯示運動參與程度愈高者有較佳的「自我表達 能力」、「自我情緒認知」、與「自我肯定能力」, 此與 Fox (2000) 所指出的從事運動可提昇個人的自我價值、自 我知覺、以及自尊等效益相呼應。在運動與人際技能方面, Smith (2003) 研究指出身體活動有助於學生在同磎間的人 際關係, 經由本研究結果, 顯示運動時間較多之大學生, 其 在人際技能表現中, 無論是「同理心」、「人際關係」、或 「社會責任」, 表現皆較優異。在運動與壓力管理之相關研 究方面, Dishman (1985) 指出運動會增加腦啡 (enkephalin) 及 $\beta$-內啡呔 (beta-endorphins) 的分泌, 這些神經傳 導物質會降低疼痛的感覺及壓力自律反應, 進而導致心理狀 態的改善, 因此運動對於壓力處理有其重要性, 本研究亦發 現, 高運動參與程度者有較佳的「涯力容忍度」。 


\section{二、大學生體育課參與情況在 $\mathrm{EQ}$ 表現上的差異}

本研究結果顯示, 參與體育課的大學生在整體 $\mathrm{EQ}$ 能力 表現優於無參與體育課程之大學生, 並顯示在「自我表達能 力」、「自我提提能力」、「人際關係」、「順應能力」、

「壓力容忍度」、「穩定性」、「快樂感」、及「樂觀指 數」八個因子上, 於本研究中已被確認; 並與其他相關研究 之結果一致。Kerr and Kuk (2001) 探討38名荷蘭大學 男生在持續參與每星期四次, 連續十週的大學體育課程的心 理影響, 並發現大學生在課程後其快樂情緒有顯著的增加, 而負面情緒則顯著減少。Hellison (2003) 認為體育環境對 大學生情緒的學習與發展相當重要, 因為體育課是兼具情感 及互動的特質, 對某些學生來説是有相當高的吸引力。體育 課程, 經由遊戲, 運動、訓練、及非正式的討論與互動過 程中提供了讓個人表現其性格及社交技能的機會 (Hellison, 2003) 。

參與體育課之大學生在「自我提昇能力」與「人際技 能」皆㙷著高於無參與體育課者之研究結果, 驗證了Ennis and Chen (1993) 所發現之研究結果: : 大學生藉由參與體 育課程, 「自我實現取向」及「社會重建取向」得以建立及 提昇。本研究之另一結果, 參與體育課之大學生無論在自我 的「獨立性」方面, 或「社會責任」、「解決問題能力」等 社會技能方面, 皆沒有顯著高於無參與體育課之大學生則與 Ennis and Chen (1993) 之發現有異; Ennis and Chen (1993) 認為「社會重建取向」旨在培養學生責任感、學習人 際互動與溝通的社交技巧以及尊重他人的意見; 此表示國內 大學之體育教育, 在教授學生各項運動技能之同時, 更需要 加強「社會責任」層面之學習, 才能得以貫徹體育課程最終 的情意教學之目標。

\section{伍、結論與建議}

\section{一、結論}

（一）大學生運動參與程度較高者, 在情緒智力 (EI) 上比運 動參與程度較低者有較佳的表現。

(二) 同時, 大學生參與體育課程者之EQ比無參與體育課程 者高。參與體育課程者在「自我技能」的表現上, 有 較高的自我肯定能力與自我提昇力; 在「人際技能」 方面, 有較佳的人際關係; 在「適應性」方面, 比無 參與體育課程之大學生較能調整自我感情、思想、 行為以適應外在環境及形式。最後在「普遍心情」 的比較上, 參與體育課程者的心理較快樂及樂觀。

\section{二、建議}

（一）在研究設計方面, 應採取運動介入方式之實驗設計, 才 能進一步驗證是否能夠經由運動之參與, 而提昇個人之 EQ能力。
(二) 在研究對象方面, 應考虑受試者之年級差異, 以同年級 大學生為研究對象, 除去不同年級之成熟度對 $\mathrm{EQ}$ 能力 影響之差異, 此外在取樣上, 各變項之組別人數分配應 平均。

（三）在名詞的界定上, 應以「身體活動 (physical activity)」取代「運動（exercise)」做為評量之依據，其所涵 蓋之範圍較廣, 也較能準確計算受試者之總活動量, 並 推算其實際之熱量消耗; 始能對運動參與程度作比較嚴 謹之分類；

(四) 在研究工具方面, BarOn EQ-i具有良好之信效度, 在 國際間也用於許多情緒智力方面之相關研究上, 但用於 台灣本研究則為首例, 整體信度雖然頗高, 但仍有少部 分分量表之信度偏低, 因此建議在使用上, 應與多元健 康機構 (Multi-Health Systems, MHS) 商討, 組成翻 譯小組, 修定原先之香港中文版本, 使其更適合國人閲 讀, 並取得更高之信度。

\section{伍、參考文獻}

王財印（2000）。國民中學學生情緒智力、生活適應與學業成 就關係之研究。未出版碩士論文, 國立高雄師範大學, 高雄市。

李孟儒（2001）。台南縣國民中學生情緒智力、生活適應與自 殺傾向之相關研究。未出版碩士論文, 國立高雄師範大 學, 高雄市。

張宏亮（1995）。運動與情緒。國民體育季刊，24(4)，4350 。

Bandura, A. (1996). Self-efficacy in Changing Societies. New York: Cambridge University.

BarOn, R. (2002). BarOn Emotional Quotient Inventory Technical Manual. New York: Multi-Health Systems.

Biddle, S. (2000). Exercise, emotions, and mental health. In Y. L. Hann (Ed.) Emotions in Sport (pp. 267292). Champaign, IL: Human Kinetics.

Biddle, S. J. H., \& Mutrie, N. (2001). Psychology of physical activity: Determinants, well-being and interventions. New York: Routledge.

Dishman, R. K. (1985). Physical activity and public health: Mental health. Quest, 47, 362-385. 
Ennis, C. D., \& Chen, A. (1993). Domain specifications and content representativeness of the revised value orientations inventory. Research Quarterly for Exercise and Sport, 64, 436-446.

Estivil, M. (1995). Therapeutic aspects of aerobic dance participation. Health Care for Women International, 16, 341-350.

Fox, K. R. (2000). Self-esteem, self-perceptions and exercise. International Journal of Sport Psychology, $31,228-240$.

Goleman, D. (1995). Emotional intelligence: Why it can matter more than IQ. New York: Bantam Books.

Hellison, D. (2003). Teaching responsibility through physical activity. Champaign, IL: Human Kinetics.

Kennedy, M. M., \& Newton, M. (1997). Effect of exercise intensity on mood in step aerobics. Journal of Sports Medicine and Physical Fitness, 37, 200204.

Kavussanu, M., \& McAuley, E. (1995). Exercise and optimism: are highly active individuals more optimistic. Journal of Sport and Exercise Psychology, 17, 246-258.

Lazarus, R. S., \& Lazarus, B. N. (1994). Passion and Reason: make sense of our emotions. New York: Oxford University Press.

Kerr, J. H., \& Kuk, G. (2001). The effects of low and high intensity exercise on emotions, stress and effort. Psychology of Sport and Exercise, 2, 173-186.

Mayer, J. D., \& Salovey, P. (1997). What is emotional intelligence. Emotional development and emotional intelligence: Educational implications. New York: Basic Books.

McGowan, R. W., Pierce, E. F., \& Jordan, D. (1991). Mood alterations with a single bout of physical activity. Perceptual and Motor Skills, 72, 1203-1209.

O'Connor, R. M., \& Little, I. S. (2003). Revisiting the predictive validity of emotional intelligence: selfreport versus ability-based measures. Personality and Individual Differences, 35, 1893-1902.

Pelliteri, J. (1999). The relationships between emotional intelligence, cognitive reasoning and defense mechanisms. Unpublished doctoral dissertation, School of Education, New York University.
Perry, P. M. (2001). Get emotional about it. Research Technology Management, 44(2), 56-58.

Petrides, K. V., \& Furnham, A. (2001). Trait emotional intelligence: psychometric investigation with reference to established trait taxonomies. European Journal of Personality, 15, 425-448.

Petrides, K. V., Frederickson, N., \& Furnham, A. (2004). The role of trait emotional intelligence in academic performance and deviant behavior at school. Personality and Individual Differences, 36, 277-293.

Slaven, L., \& Lee, C. (1997). Mood and symptom reporting among middle-aged women: The relationship between menopause status, hormone replacement therapy, and exercise participation. Health Psychology, 16(3), 203-208.

Smith, A. L. (2003). Peer relationships in physical activity contexts: a road less traveled in youth sport and exercise psychology research. Psychology of Sport and Exercise, 4(1), 25-39.

Szabo, A. (2003). The acute effects of humor and exercise on mood and anxiety. Journal of Leisure Research, 35(2), 152-162.

Turnbull, M., \& Wolfson, S. (2002). Effects of exercise and outcome feedback on mood: evidence for misattribution. Journal of Sport Behavior, 25(4), 394406.

Yeung, R. R. (1996). The acute effects of exercise on mood state. Journal of Psychosomatic Research, 40, 123-141.

\section{聯 絡}

\begin{tabular}{|c|c|}
\hline 作者姓名 & : 李淑芳、王秀華、廖崉甯 \\
\hline 所屬單位 & : 國立中正大學運動休閒教育研究所 \\
\hline \multicolumn{2}{|c|}{ 主要聯絡者 : 王秀華 } \\
\hline \multirow[t]{2}{*}{ 通訊地址 } & : 嘉義縣621民雄鄉大學路 168號 \\
\hline & 運動休閒敎育研究所 \\
\hline 電話 & :(05)272-0411＼cjkstart分機：37511 \\
\hline 傳真 & $:(05) 2721054$ \\
\hline & $: 0952422818$ \\
\hline na & :grcsww@ccu.edu.tw \\
\hline
\end{tabular}

